\title{
INTEGRATED MANAGEMENT SYSTEMS DIFFUSION MODELS IN SOUTH EUROPEAN COUNTRIES
}

\section{STRUCTURED ABSTRACT}

Purpose - This paper dissects the diffusion of the number of organizations that implemented multiple management systems (MSs), considering the ISO 9001, ISO 14001 and OHSAS 18001 standards (QES) in the South European countries: Italy, Portugal and Spain. In addition, based on the data collected, forecasting models were developed to assess at which extent the multiple certifications are expected to occur in each studied country.

Design/methodology/approach - Data concerning the evolution of the amount of multiple MSs in Italy, Portugal and Spain were collected for the period between 1999 and 2015. The behaviour of the evolution of the number of MSs over the years was studied adopting both the Gompertz and the Logistic models. The results obtained with these two models were compared and analyzed to provide a forecast for the next years.

Findings - The diffusion throughout the years of the number of MSs presents an Sshaped behaviour. The evolution of the amount of MSs in countries with a lower saturation level are properly fitted by the Gompertz model whereas the Logistic model fits more accurately when considering countries with a larger saturation level.

Research limitations/implications - The data related to the early years are not available in some of the countries. To overcome this shortcoming missing data was extrapolated from the dataset provided by the annual ISO survey. Additionally, the integration level attained by each company was not assessed and, on this regard and in the scope of this paper, an integrated management system is understood as implemented when organizations have multiple MSs implemented.

Practical implications - The results provide a cross-sectional portrayal of the diffusion of MSs certifications in the South European countries and enable a forecast for the trend in the next years.

Originality/value - This study aims for the first time, to the best of the authors' knowledge, to analyze the diffusion of multiple MSs throughout the years. 
Keywords: Management systems, Integrated Management Systems (IMSs), Diffusion model, Logistic model, Gompertz model.

Paper type: Research paper 


\section{INTRODUCTION}

The concerns of the organizations related with new stakeholders and their requirements have increased over the last few years. Hence, organizations seek to address these new requirements through the adoption and implementation of different certification standards, which leads to the coexistence of multiple management systems (see ISO, 2017). The International Organization for Standardization (ISO) publishes annually the ISO Survey of Certifications with data concerning the number of certificates issued, breakdown by management standard, each year (ISO, 2017).

So far, several authors have analysed the individual diffusion of the most widely implemented and well known standards such as the ISO 9001 (Albuquerque et al., 2007; Franceschini et al., 2004; Sampaio et al., 2009) and ISO 14001 (Corbett and Kirsch, 2001; Qi et al., 2011; To and Lee, 2014; Vastag, 2004). This research enabled the development of forecasting models, highlighted the features that seem to promote a successful diffusion of certificates, outlined the path to sustainable certification and pointed out those countries where a saturation level apparently was reached.

The integration of these management subsystems (MSs) into a single system of systems is being carried out by an increasing amount of companies, adopting different strategies and attaining different integration levels (Abad et al., 2014; Bernardo et al., 2017a; Karapetrovic et al., 2006). From an academic point of view this is a broad research field that has been explored extensively by management scholars. However, data related to the number of Integrated Management Systems (IMSs) are not available in this or any other international publication. Thus, this paper intends to report the first efforts of a work in progress that ultimately focus on the development of a forecasting model that may explain the diffusion of IMSs in South European Countries. This paper aims at answering relevant 
questions related to the diffusion of the IMSs, such as: (i) How has IMSs diffusion evolved over time? (ii) How is it expected to evolve later on? (iii) Do different countries in the same region, present the same behaviour?

Therefore, the development of a similar work focusing on IMSs would bring some light on unexplored features disclosing the current path and some of the challenges yet to come. It should be highlighted that the data supporting the results of the current paper concerns solely with the number of organizations simultaneously operating and certified according to the ISO 9001, ISO 14001 and the OHSAS 18001 standards (QES) regardless and irrespective the attained integration level of the MSs. A theoretical sampling of three South European countries, namely Italy, Portugal and Spain, took place in order to consider the geographic context impact on the results.

In addition to this brief introduction, the remainder of the paper is structured as follows: Section 2 reports the analysis of the existing scientific literature about IMSs and the diffusion of certifications according to international management system standards; Section 3 describes the research method adopted in the present work and Section 4 presents the main results. The last section is devoted to the discussion of the main findings and to the identification of some elements for the future work.

\section{LITERATURE REVIEW}

This section addresses the main studies on both the integration of MSs and MS standards diffusion. The mathematical dynamics of the tested growth curves used as diffusion models are explained at the end of the section. 


\section{Integrated Management Systems}

Nowadays, the implementation of multiple MSs is increasing (Bernardo et al., 2011), aiming at effectiveness, improved efficiency and stakeholder assurance (Bernardo et al., 2015; Karapetrovic et al., 2006).

The recurring themes addressed in the mainstream literature within the IMSs scientific domain reported the limitations of the lack of integration (Almeida et al., 2014; Domingues et al., 2012, 2014), enabled the identification of critical success factors (Almeida et al., 2014; Oliveira, 2013) and dissected the guidelines and strategies for integration of MSs (Oliveira, 2013; Rebelo et al., 2014a). In addition, several authors proposed some contributions on the proper design of IMSs (Garengo and Biazzo, 2013; Manzanera et al., 2014; Rebelo et al., 2014b; Zeng et al., 2007), on the factors that impact the integration level attained (Bernardo et al., 2011, 2012) and suggested integration levels or degrees (Bernardo et al., 2009; Jørgensen et al., 2006; Jørgensen, 2008; Sampaio et al., 2012). The potential relationships between different MSs was a topic addressed by Domingues et al. (2011a, 2011b) and Karanikas (2014) and some authors pointed out both the difficulties and benefits of the development of IMSs (Bernardo et al., 2015; Sampaio et al., 2012; Simon et al., 2012; Zeng et al., 2011).

The interest in recent research focuses on the linkages between the integration phenomenon and other managerial practices. On this note, for example, Bernardo (2014) presented the development of a model aiming at the analysis of the relationship between integration of MSs and innovation management performance or integration performance (see also Hernandez-Vivanco et al., 2016), Ferrón-Vílchez and Darnall (2016) dissected the relationship between the adoption of MSs and business performance (see also MartíBallester and Simon, 2017), Gianni and Gotzamani (2015) listed the lessons learned from 
abandonment cases of IMS and Mežinska et al. (2015) proposed some guidelines on how to design an IMS aiming at a socially responsible organization (see also Gianni et al., 2017).

\section{Management systems diffusion}

The growth and diffusion process was studied by several authors, focusing on the patterns in terms of future trends or distribution functions in many areas, such as Biology, Innovation and Economy (Carrillo and González, 2002; Meade and Islam, 2006). The study of the diffusion phenomenon of MS standards is not new. Several authors have studied the diffusion of the ISO 9001 (Franceschini et al., 2004; Viadiu et al., 2006; Albuquerque et al., 2007; Chen and Liu, 2009; Cots and Casadesús, 2015; Marimon et al., 2009; Sampaio et al., 2011; Salgado et al., 2015), ISO 14001 (Albuquerque et al., 2007; Casadesús et al., 2008; Viadiu et al., 2006; Qi et al., 2011; Delmas and MontesSancho, 2011; Heras-Saizarbitoria et al., 2015; Hikichi et al., 2017; To and Lee, 2014), ISO/TS 16949 (Franceschini et al., 2011) and SA 8000 (Llach et al., 2015) standards. In addition, comparison of these generic MS standards with sectoral standards has been analysed (Alonso-Almeida et al., 2013 ; Bernardo et al., 2017b).

Among other results, it was found that ISO 9001 diffusion is motivated by geography and bilateral trade relations whereas the ISO 14001 diffusion is motivated by geography and cultural proximity (Albuquerque et al. 2007). Besides it was found a positive relationship between the number of the issued certificates ISO 9001 in each country per 1000 inhabitantes and the economic development indicators (Salgado et al., 2015; Sampaio et al., 2011). Some studies also showed similarities between the behaviour of the evolution 
of the ISO 9001 implementation and the evolution of the ISO 14001 implementation. (Casadesús et al., 2008).

In the study of the standards diffusion some authors, based on the data available, described the path of the diffusion certification process as S-shaped, similarly to the behaviour of the bio-population growth curve in limited resource habitat or to a diffusion process of technologies (Chen and Liu, 2009; Franceschini et al., 2004). It should be mentioned that different forecasting models were tested in different domains with different degrees of success (Carrillo and González, 2002; Meade and Islam, 1995). More recently the study of the evolution of the certification process was also targeted and several authors reported the fitting of the logistic curve (the most widely adopted growth curve) in the case of certified MSs diffusion (Alonso-Almeida et al., 2013; Franceschini et al., 2011; Franceschini et al., 2004; Llach et al., 2015; To and Lee, 2014; Viadiu et al., 2006).

These studies allowed to know which is the state of the phenomenon of the standards diffusion and when the saturation will be achieved (Franceschini et al., 2004; Viadiu et al., 2006; Chen and Liu 2009; To and Lee 2014).

\section{Growth Curves- Logistic and Gompertz models}

One of the critical assumptions in the adoption of growth curves for forecasting is whether the curve fitted is the proper one (Martino, 1993). A careful analysis should be considered to assure that the chosen growth curve match and mimics the growth dynamics of the phenomenon observed. Thus, the behaviour of the curve when extrapolated outside the range data will match the future behaviour of the phenomenon (Martino, 1993). 
Many models may be adopted to fit S-shape behaviours. However, in the current paper we contemplate solely the logistic curve (applied in Franceschini et al., 2004; Llach et al., 2011; Alonso-Almeida et al., 2013, among other certification diffusion studies), and the Gompertz model, which has been proposed in some studies in the domain of biology and innovation due to its good performance when describing the path of the data analysed (Meade and Islam, 1995; Zwietering et al., 1990). Other forecasting models were reported in the scientific literature such as those authored by Carrillo and González (2002), Meade and Islam (1998) and Zwietering et al. (1990).

The adoption of these two models. Logistic curve and Gompertz, is supported by the evidence that the certification process behaves very similar to a bio-population growth in a limited resource habitat, or to a diffusion process of new technologies. According to Buchanan et al. (1997), Franceschini et al. (2004) and Martino (1993), three phases are distinguishable and encompass each growth curve of both the Gompertz and Logistic models:

(1) Lag phase: The early development of the diffusion of MSs certification. Some companies aiming to distinguish themselves among the business competition, provide an external and formal evidence of their organizational efforts towards quality practice, environment and health and safety concerns. Simultaneously, organizations are confronted with the initial difficulties of the implementation. Also named initial stage.

(2) Exponential phase: steeper and sudden growth, achieving success in a more and more careful market, their number progressively grows up with a trend almost exponential and the initial difficulties of the implementation are overcome. Deeper and increased concern of the organizations towards the certification, notably, on the assessment of the results obtained: 
- inside of the organization itself, increasing the resource involvement;

- outside, giving to their stakeholders the evidence of excellence achievement.

Nevertheless, the increasing process does not go on without end. Caught up the interest apex, the driving push slowly attenuates impacted by some concomitant factors: the reduction of the competitive gap between certified and non-certified organizations, and the limited number of organizations potentially looking forward the certification. Also known as growth or taking-off stage.

(3) Stationary phase: The growth slowdown and the maximum value is achieved. Also named saturation or maturity stage.

However, some studies, such as Franceschini et al. (2010) and Marimon et al. (2009), found that some organizations were abandoning the certification and a fourth stage was defined: the decline or decertification stage.

\section{MATERIALS AND METHODS}

The sample and its analysis are explained in this section.

\section{Sample}

The majority of diffusion studies commented previously has used the data from the ISO survey, thus, they are based on the number of certificated reported in the survey (see e.g., Casadesús et al., 2008; Marimon et al., 2009; Llach et al., 2011). However, as previously mentioned there is a lack of information, directly accessible, either public or private, concerning the IMSs data. It is important to mention that IMS cannot be internationally 
certified as the analysed MS standards (Bernardo et al., 2017a). Thus, any attempt to use the same methods to analyse the IMS diffusion should use a proxy variable.

Regarding the countries selection, Spain and Italy have ranked in the top four worldwide positions regarding the certification of both ISO 9001 and ISO 14001 during several years (see ISO, 2017). Portugal certifications in these MS standards have growth continuously in recent years increasing the number of certified organizations (see Domingues et al., 2017; ISO, 2017).

Hence, the local certification bodies operating in Portugal and Spain were contacted to provide the information available regarding the number of certified IMSs. In the Italian case, the data was retrieved from the on-line database of Italian accreditation body ACCREDIA. Table 1 summarizes the data collection process. The "number of certificates” represents the valid certificates annually issued in the studied period. This implies that decertifications are also considered and, thus, data is regularly updated. The “number of companies” reflects the number of certified organizations (neither the number of certified sites nor the number of certificates). There is a substantial difference between the "number of certificates" and the "number of certified companies", in fact a single company may hold more than one certificate. However, in our specific situation, this difference is negligible and does not influence the results of this analysis.

[Table 1 near here]

In this study data refer to MSs simultaneously certified (QES, i.e. Quality, Environment and Safety) according to the ISO 9001, ISO 14001 and OHSAS 18001 standards, not 
considering their level of integration. However, it must be highlighted that the required data for the whole time interval from 1999 to 2015 was not available for some of the analysed countries. Hence, to obtain, at least, an estimate of data from 1999 until 2013 for the considered countries, the missing values for Portugal and Spain were estimated by extrapolating them from the ISO survey (ISO, 2017). Table 2 presents the raw data collected and adopted to populate the forecasting models.

[Table 2 near here]

\section{Analysis of data: models}

The Gompertz curve is an S-shaped model asymmetric relatively to the inflection point widely adopted in the scientific literature. The value "a” (saturation value) notes the maximum number of organizations that potentially may achieve certification (MarMolinero, 1980; Meade and Islam, 1995; Carrillo and González, 2002). Figure 1 displays the usual shape of the Gompertz curve.

[Figure 1 near here]

The differential equation describing the Gompertz model (1) and the solution (2) are expressed as (Carrillo and González, 2002; Winsor, 1932; Wu and Chu, 2010; Zwietering et al., 1990):

$$
\begin{gathered}
\frac{d y}{d t}=k * y * \ln \left(\frac{a}{y}\right) \text { or } \frac{\frac{d y}{d t}}{y}=k * \ln \left(\frac{a}{y}\right) \\
y(t)=a \cdot e^{-e^{\left[-k \cdot\left(t-t_{c}\right)\right]}}
\end{gathered}
$$


where $\mathrm{k}$ is a mathematic parameter of the model and represents the time when the curve reaches the inflection point, that can be calculated by equation (3) (Winsor, 1932).

$$
t_{c}=\frac{t_{a}}{e}
$$

The Simple Logistic Curve is one of the most adopted fitting curves in the literature. This model differs from the Gompertz curve since it is symmetric relatively to the point of inflection. This means that half of the saturation level is reached at the inflection point (Carrillo and González, 2002; Franses, 1994; Mar-Molinero, 1980; Meade and Islam, 1995). The Logistic differential is presented by the equation (4) (Carrillo and González, 2002; Winsor, 1932; Wu and Chu, 2010; Zwietering et al., 1990):

$$
\frac{d y}{d t}=k \cdot y \cdot\left(1-\frac{y}{a}\right) \text { or } \frac{\frac{d y}{d t}}{y}=k \cdot\left(1-\frac{y}{a}\right) \text { or } \frac{\frac{d y}{d t}}{y}=k \cdot \frac{y}{a}
$$

which has the following solution (Simple Logistic Curve) (Carrillo and González, 2002; Winsor, 1932; Wu and Chu, 2010; Zwietering et al., 1990):

$$
y(t)=\frac{a}{1+e^{\left[-k \cdot\left(t-t_{c}\right)\right]}}
$$

Like in the Gompertz curve, $\mathrm{k}$ is a mathematic parameter of the model and tc typify the time when the inflection point is reached. Figure 2 portrays the usual shape of the Logistic curve. In this case, the more the data disposition is symmetrical regarding the inflection point the more the fit is accurate.

[Figure 2 near here] 
The non-linear least squares regression (Seber and Wild, 1989; Martino, 1993; Meade and Islam, 1995; Zwietering et al., 1990) is the most effective approach for fitting Gompertz or Logistic curves. In the present work, the "Non-linear curve fits" function of the software Origin ${ }^{\circledR} 2016$ was adopted. The performance of the fit is impacted by the information present in the data used for the estimation. In particular, the result is affected by the number of collected observations and by the inclusion of the inflection point in the range of variation of the data (Meade and Islam, 1998).

\section{RESULTS AND DISCUSSION}

The models for forecasting and analysing the current state of QES were developed considering the data in Table 2 and using the second column (“Counter”) as independent variable. The parameters of each model applied to different countries are reported in Tables 3 and 4. With these data and the graphics presented in Figures 3 to 8, it is possible to observe that the studied countries reach different levels of growth.

Considering the Spanish results, it is possible to conclude that this country already achieved the saturation level (in line with previous results, such as Alonso-Almeida et al., 2017; Bernardo et al., 2017b). Studying the statistic parameters of this country both models presents a good fitting of data and the final values of the saturation level respectively obtained with these two models do not present any significant difference. Therefore, it is possible to assume and expect similar results by applying these two models to countries that reached the saturation level. Observing the Residual Sum of Squares, it is also possible to conclude that, in the Spanish case, the Logistic model describes better the current dynamic of growth. As commented before, Spain has been ranked as an intensive certifier country during years (see ISO, 2017) and the experience gained during 
this period could help in having a better IMS management (Bernardo et al., 2017a). In addition, according to the existing literature, Spanish organizations are more oriented to integrate their MSs (see e.g., Bernardo et al., 2009; Simon et al., 2011), and this could explained the saturation stage, following the individual MS standards diffusion.

[Tables 3 and 4 near here]

The results from Portugal and Italy suggest that both countries are positioned in the exponential or growth phase of the curve and very dissimilar results are obtained when applying each model. For Italy (see also Casadesús et al., 2008), it is quite obvious which forecasting model is fitting better based on the currently available data: the saturation level predicted by the Gompertz curve is unrealistic. This may be explained by the development of the model and by the fact that it assumes that the data used do not reached the inflection point and it is far from that, in the case of Gompertz. Furthermore, observing the Residual Sum of Squares, it is possible to confirm that the Logistic model performs much accurately than the Gompertz one. With further information (future available data) better fitting results may be expected. Italy has also ranked in the first positions of worldwide certificates of ISO 9001 and ISO 14001 but the studies about the integration of MSs are not numerous and the existing literature are not considering all the MSs analysed in this paper (see e.g., Botta et al., 2013; Garengo and Biazzo, 2013; Proto et al., 2013).

Looking at the Portuguese data, it seems that Gompertz curve provides better statistic results than the Logistic curve. This is further confirmed by the Residual Sum of Squares. Thus, it is possible to conclude that the Gompertz curve describes accurately the dynamics 
of QES growth in the case of Portugal. According to Domingues et al. (2017), the number of certificates of the individual MS standards analysed has grown on the last decade, reaching the saturation level. In addition, based on the existing literature, the interest in the integration of MSs has also increased (see e.g., Domingues et al., 2017; Ribeiro et al., 2017), thus the diffusion of these practices are increasing.

When comparing Portugal and Italy, the selected models respectively predict that Italy will achieve the saturation level approximately in 2025, while Portugal is still in the growing phase. This is an expected result, since Portugal presents a slower growth pace compared to Italy. When observing the current results, it seems that Gompertz curve fits more accurately the dynamics of countries with lower saturation level whereas the Logistic-fitting curve seems the proper model to describe diffusion of the countries with higher saturation level. These results will be improved and updated throughout the years, since, as mentioned previously, the performance of the model is determined by the amount of provided information, i.e., by the number of data and their positioning throughout the curve shape (Meade and Islam 1998).

[Figures 3 to 8 near here]

\section{CONCLUSIONS}

Based on the gathered data, it is possible to conclude that despite the geographic proximity between the countries that were considered in this research (all of them being South European) cross-country results show significant dissimilarities with regard to QES evolution. However, there is a similar growing trend in the percentage of ISO 9001 used in the QES across the countries. In the case of Spain, this happens due to the decrease of 
ISO 9001 certification rates in the last years. In the case of Portugal and Italy, based on the data collected, the implementation of ISO 9001 has increased, and the \% QES/ISO 9001 has increased, as well, which means that, in the last few years, domestic organizations seem to decide to integrate more.

Concerning the forecasting models, Gompertz and Logistic, results suggest that Spain reached the QES saturation level and although similarities among the results of both models it seems that the Logistic model accurately fits the Spanish data. When both models are applied to the countries located in the exponential phase, i.e., Portugal and Italy, the results are very dissimilar. In order to define which one is the best fit model in this case, more research is needed to study the trends of the countries and the factors that impact on the diffusion within these countries, with respect to QES.

Although the uncertainty ascribed to the results (due to study limitations) it is possible to state that, based on the data, the first country that achieved the saturation phase was Spain in 2011 and the saturation level predicted was of 2421 certifications, followed by Italy that will reach the saturation phase in approximately 2032, reaching a maximum of 3709 certifications and, finally, Portugal that will reach the saturation phase in 2044 with a maximum of 1945 certifications. It should be mentioned that the uncertainty associated with the results will be minimize yearly by updating the results.

In general, one may conclude that a single model does not fit all the paths described for the countries studied. The lack of information relatively to the IMS is the main limitation of the present study. The only country where data extension was available was Italy since IMSs data from 1999 to 2013 were available. In the case of Portugal, it was needed to 
extrapolate data from 1999 to 2007. In the Spanish case, data for the years since 2008 to 2014 were estimated based on the AENOR and ISO survey data, and it was needed to extrapolate data for the previous years. These estimations and extrapolations introduced some uncertainty in the results. The organizations with other MSs integrated (in number and/or typologies) are not included. For instance, the IMSs that have two MSs integrated, e.g. ISO 9001 and ISO 14001 or ISO 9001 and OHSAS 18001 or ISO 9001 and ISO 22000 etc., are not taken into account. Furthermore, the data that was collected and computed represent the number of companies that are generally "simultaneously certified" with the three MS standards and/or hold three MS standard certificates. However, there might be a difference between the merely "simultaneously certified” and the "integrated" management systems, meaning that the degree of integration of the individual MSs is not assessed in the framework of this study.

However, to the best of the authors' knowledge, this is the first attempt to analyse empirically the diffusion of IMS. More research is needed to define better the proxy variable used, considering the limitations with the data. Related to the academia implications, this paper contributes to evidence the similarity of IMS and an individual MS standard evolution. For managers, the paper contributes as a benchmarking tool because they could know how the country organizations behave regarding MSs management. Finally, as more MSs organizations implement and integrate, better the management will be and this will impact on an improved economy, development and also in more satisfied stakeholders.

Future research on IMSs would further highlight whether the trend of the concurrent implementation of more than one standard is increasing and which will be the impact of 
the revisions of the standards in the current trends. Another interesting research topic is the impact of the OHSAS 18001 turning into an ISO standard on QES evolution. Furthermore, the study of IMSs diffusion across more countries may lead to more robust conclusions, shedding light on possible causes for the different state and dynamics of growth.

\section{AKNOWLEDGEMENT}

The authors would like to thank the collaboration of several certification entities. This study had the financial support of FCT- Fundação para a Ciência e Tecnologia of Portugal under the project UID/CEC/00319/2013. Pedro Domingues is supported by FCT PostDoc Grant Reference SFRH/BPD/103322/2014.

\section{REFERENCES}

Abad, J., Dalmau, I. \& Vilajosona, J., 2014. Taxonomic proposal for integration levels of management systems based on empirical evidence and derived corporate benefits. Journal of Cleaner Production. 78, 164-173.

Albuquerque, P., Bronnenberg, B.J. \& Corbett, C.J., 2007. A Spatiotemporal Analysis of the Global Diffusion of ISO 9000 and ISO 14000 Certification. Management Science, 53(3), pp.451-468.

Almeida, J., Domingues, P. \& Sampaio, P., 2014. Different perspectives on management systems integration. Total Quality Management \& Business Excellence, 25(4), pp.338-351.

Alonso-Almeida, M. del M., Marimon, F. \& Bernardo, M., 2013. Diffusion of quality standards in the hospitality sector. International Journal of Operations \& Production 
Management, 33(5), pp.504-527.

Bernardo, M., 2014. Integration of management systems as an innovation: a proposal for a new model. Journal of Cleaner Production, 82, pp.132-142.

Bernardo, M., Casadesus, M., Karapetrovic, S. \& Heras, I., 2009. How integrated are environmental, quality and other standardized management systems? An empirical study. Journal of Cleaner Production, 17(8), pp.742-750

Bernardo, M., Casadesus, M. \& Karapetrovic, S., 2011. Are methods used to integrate standardized management systems a conditioning factor of the level of integration? An empirical study. International Journal for Quality research, 5(3), pp.213-222.

Bernardo, M.e, Casadesus, M., Karapetrovic, S. \& Heras, I. 2012. Do integration difficulties influence management system integration levels? Journal of Cleaner Production, 21, pp.23-33.

Bernardo, M., Simon, A., Tarí, J.J., Molina-Azorín, J.F., 2015. Benefits of management systems integration: a literature review. Journal of Cleaner Production, 94, pp.260267.

Bernardo, M., Gianni, M., Gotzamani, K. \& Simon, A., 2017a. Is there a common pattern to integrate multiple management systems? A comparative analysis between organizations in Greece and Spain. Journal of Cleaner Production, 151, pp.121-133

Bernardo, M., Escalante, R., Roca, J. \& Arbussà, A. 2017b. Gastronomy management: A comparative analysis of the existing management system standards. International Journal of Quality \& Reliability Management, 34(2), pp.163-175

Botta, S., Comoglio, C. \& Petrosillo, I. 2013. Implementing the environmental and social 
policies of a municipality through an integrated management system: Theoretical framework and case study. Journal of Environmental Planning and Management, 56(7), pp. 1073-1095

Buchanan, R.., Whiting, R.. \& Damert, W.., 1997. When is simple good enough: a comparison of the Gompertz, Baranyi, and three-phase linear models for fitting bacterial growth curves. Food Microbiology, 14(4), pp.313-326.

Carrillo, M. \& González, J.M., 2002. A new approach to modelling sigmoidal curves. Technological Forecasting and Social Change, 69(3), pp.233-241.

Casadesús, M., Marimon, F. \& Heras, I., 2008. ISO 14001 diffusion after the success of the ISO 9001 model. Journal of Cleaner Production, 16, pp.1741-1754.

Chen, Y. \& Liu, E., 2009. The Diffusion of ISO9000 Certification in China: A Trend Analysis Based on Grey Verhulst Model. 2009 International Conference on Information Management, Innovation Management and Industrial Engineering, pp.223-226.

Corbett, C.J. \& Kirsch, D.A., 2001. International diffusion of ISO 14000 certification. Production and Operations Management, 10(3), pp.327-342..

Cots, S. \& Casadesús, M., 2015. Exploring the service management standard ISO 20000. Total Quality Management \& Business Excellence, 26(5-6), pp. 515-533

Delmas, M.A. \& Montes-Sancho, M.J., 2011. An institutional perspective on the diffusion of international management system standards: The case of the environmental management standard ISO 14001. Business Ethics Quarterly, 21(1), pp.103-132.

Domingues, J.P.T., Sampaio, P. \& Arezes, P.M., 2014. Analysis of integrated management systems from various perspectives. Total Quality Management \& 
Business Excellence, pp.1-24.

Domingues, J.P.T., Sampaio, P. \& Arezes, P.M., 2011a. Integrated Management Systems: the vision from the perspective of the Occupational Health and Safety System. In International Symposion on Occupational Safety and Hygiene.

Domingues, J.P.T., Sampaio, P. \& Arezes, P.M., 2011b. Management systems integration: should "quality” be redefined? In 55th EOQ Congress. Budapest, Hungary.

Domingues, P., Sampaio, P. \& Arezes, P.M., 2012. New organisational issues and macroergonomics : integrating management systems. International Journal of Human Factors and Ergonomics, 1(4), pp.351-375.

Domingues, J.P.T., Sampaio, P. \& Arezes, P.M., 2017a. Analysis of certified occupational health and safety management systems in Portugal. International Journal of Occupational and Environmental Safety, 1, pp.11-28

Ferrón-Vílchez, V. \& Darnall, N., 2016. Two are Better Than One: The Link Between Management Systems and Business Performance. Business Strategy and the Environment, 25(4), pp.221-240

Franceschini, F., Galetto, M., Maisano, D.A. \& Mastrogiacomo, L. 2011. ISO/TS 16949: analysis of the diffusion and current trends. Proceedings of the Institution of Mechanical Engineers, Part B: Journal of Engineering Manufacture, 225, pp.735745.

Franceschini, F., Galetto, M. \& Gianni, G., 2004. A new forecasting model for diffusion of ISO 9000 standard certifications in European countries. International Journal of Quality \& Reability Management, 21(1), pp.32-50.

Franceschini, F., Galetto, M., Maisano, D. \& Mastrogiacomo, L. 2010. Clustering of 
European countries based on ISO 9000 certification diffusion. International Journal of Quality \&Reliability Management, 27(5), pp. 558-575

Franses, P.H., 1994. Fitting a Gompertz curve. Journal of the Operational Research Society, 45(1), pp.109-113.

Garengo, P. \& Biazzo, S., 2013. From ISO quality standards to an integrated management system: an implementation process in SME. Total Quality Management \& Business Excellence, 24(3-4), pp.310-335.

Gianni, M. \& Gotzamani, K., 2015. Management systems integration: lessons from an abandonment case. Journal of Cleaner Production, 86, pp.265-276.

Gianni, M., Gotzamani, K., \& Tsiotras, G., 2017. Multiple Percpectives on Integrated Management Systems and Corporate Sustainability Performance. Journal of Cleaner Production, 168, pp. 1297-1311Heras-Saizarbitoria, I., Arana, G. \& Boiral, O., 2015. Exploring the dissemination of environmental certifications in high and low polluting industries. Journal of Cleaner Production, 89, pp. 50-56

Hernandez-Vivanco, A., Bernardo, M. \& Cruz-Cázares, C., 2016. Relating open innovation, innovation and management systems integration. Industrial Management \& Data Systems, 116(8), pp.1540-1556

Hikichi, S.E., Salgado, E.G., \& Beijo, L.A., 2017. Forecasting number of ISO 14001 certifications in the Americas using ARIMA models. Journal of Cleaner Production, 147, pp. 242-253

ISO, 2017. ISO survey of Certifications 2016, International Organization for Standardization, Geneva, Switzerland 
Jørgensen, T.H., 2008. Towards more sustainable management systems: through life cycle management and integration. Journal of Cleaner Production, 16, pp.10711080.

Jørgensen, T.H., Remmen, A. \& Mellado, M.D., 2006. Integrated management systems - three different levels of integration. Journal of Cleaner Production, 14, pp.713722.

Karanikas, N., 2014. Defining the Interrelationship between Safety and Quality Management Systems. International Journal of Management, 3(1), pp.51-60.

Karapetrovic, S., Casadesús, M., Heras, I. 2006. Dynamics and integration of standardized management systems. An empirical study, Documenta Universitaria. GITASP 1, Girona, Spain.

Llach, J., Marimon, F. \& Alonso-Almeida, M. del M., 2015. Social Accountability 8000 standard certification: analysis of worldwide diffusion. Journal of Cleaner Production, 93, pp.288-298.

Llach, J., Marimon, F. \& Bernardo, M., 2011. ISO 9001 diffusion analysis according to activity sectors. Industrial Management \& Data Systems, 111(2), pp.298-316.

Manzanera, R., Jardí, J., Gomila, X., Pastor, J.R., Ibáñez, D., Gálvez, G., Albertí, C., Navarro, A., Uris, J., Pomares, A., López, L., Zuazu, C., Sabaté, P., Aguado, I., Domingo, L., Infante, C., Gomis, J., Jover, A., Iglesias, J. \& Mestres, A., 2014. Design of an integrated management system (IMS) in a government-run medical evaluation organisation. The TQM Journal, 26(6), pp.550-565

Mar-Molinero, C., 1980. Tractors in Spain: a Logistic Analysis. Journal of the Operational Research Society, 31(2), pp.141-152. 
Marimon, F., Heras, I. \& Casadesús, M., 2009. ISO 9000 and ISO 14000 standards: A projection model for the decline phase. Total Quality Management \& Business Excellence, 20(1), pp.1-21.

Martí-Ballester, C.P. \& Simon, A., 2017. Union is strength. Management Decision, 55(1), pp.81-102

Martino, J.P., 1993. Technological forecasting for decision making Third Edit. M. K. Badawy, ed.,

Meade, N. \& Islam, T., 1995. Forecasting with growth curves: An empirical comparison. International Journal of Forecasting, 11(2), pp.199-215.

Meade, N. \& Islam, T., 2006. Modelling and forecasting the diffusion of innovation - A 25-year review. International Journal of Forecasting, 22(3), pp.519-545.

Meade, N. \& Islam, T., 1998. Technological Forecasting--Model Selection, Model Stability, and Combining Models. Management Science, 44(8), pp.1115-1130.

Mežinska, I., Lapiņa, I. \& Mazais, J., 2015. Integrated management systems towards sustainable and socially responsible organisation. Total Quality Management \& Business Excellence, 26(5-6), pp.469-481. Oliveira, O.J. de, 2013. Guidelines for the integration of certifiable management systems in industrial companies. Journal of Cleaner Production, 57, pp.124-133.

Proto, M., Malandrino, O. \& Supino, S. (2013). The implementation of integrated management system in Agri-Food SMEs. In Salomone, R. et al. (eds.), ProductOriented Environmental Management Systems (POEMS) (pp. 89-101). Dordrecht, PA: Springer Science+Business Media 
Qi, G.Y., Zeng, S.X., Tam, C.M., Yin, H.T., Wu, J.F. \& Dai, Z.H., 2011. Diffusion of ISO 14001 environmental management systems in China: rethinking on stakeholders’ roles. Journal of Cleaner Production, 19, pp.1250-1256.

Rebelo, M.F., Santos, G. \& Silva, R., 2014a. A Methodology to Develop the Integration of the Environmental Management System with Other Standardized Management Systems. Computational Water, Energy. and Environmental Engineering, 3, pp.170-181.

Rebelo, M.F., Santos, G. \& Silva, R., 2014b. Integration of Individualized Management Systems (MSs) as an Aggregating Factor of Sustainable Value for Organizations: An Overview Through a Review of the Literature. Journal of Modern Accounting and Auditing, 10(3), pp.356-383.

Ribeiro, F., Santos, G., Rebelo, M.F. \& Silva, R., 2017. Integrated Management Systems: Trends for Portugal in the 2025 horizon. Procedia Manufacturing, 13, pp.1191-1198

Salgado, E.G., Beijo, L.A., Sampaio, P., Pereira Mello, C.H. \& Saravaia, P. 2015. ISO 9001 certification in the American Continent: a statistical analysis and modelling. International Journal of Production Research, pp.1-18.

Sampaio, P., Saraiva, P. \& Domingues, P., 2012. Management systems: integration or addition? International Journal of Quality \& Reability Management, 29(4), pp.402424.

Sampaio, P., Saraiva, P. \& Rodrigues, A.G., 2009. An analysis of ISO 9000 data in the world and the European Union. Total Quality Management \& Business Excellence, 20(12), pp.1303-1320.

Sampaio, P., Saraiva, P. \& Rodrigues, A.G., 2011. ISO 9001 certification forecasting models. International Journal of Quality \& Reability Management, 28(1), pp.5-26. 
Simon, A., Karapetrovic, S. \& Casadesús, M., 2012. Difficulties and benefits of integrated management systems. Industrial Management \& Data Systems, 112(5), pp.828-846.

To, W.M. \& Lee, P.K.C., 2014. Diffusion of ISO 14001 environmental management system: Global, regional and country-level analyses. Journal of Cleaner Production, 66, pp.489-498.

Vastag, G., 2004. Revisiting ISO 14000 Diffusion: A New “Look” at the Drivers of Certification. Production and Operations Management, 13(3), pp. 260-267.

Viadiu, F.M., Fa, M.C. \& Saizarbitoria, I.H., 2006. ISO 9000 and ISO 14000 standards: an international diffusion model. International Journal of Quality \& Reability Management, 26(2), pp.141-165.

Winsor, C.P., 1932. The Gompertz Curve as a Growth Curve. Proceedings of the National Academy of Sciences, 18(1), pp.1-8.

Wu, F.-S. \& Chu, W.L., 2010. Diffusion models of mobile telephony. Journal of Business Research, 63(5), pp.497-501.

Zeng, S.X., Shi, J.J. \& Lou, G.X., 2007. A synergetic model for implementing an integrated management system: an empirical study in China. Journal of Cleaner Production, 15, pp.1760-1767.

Zeng, S.X., Xie, X.M., Tam, C.M. \& Shen, L.Y. 2011. An empirical examination of benefits from implementing integrated management systems (IMS). Total Quality Management \& Business Excellence, 22(2), pp.173-186.

Zwietering, M.H., Jongenburger, I., Rombouts, F.M. \& van 't Riet, K.1990. Modeling of the bacterial growth curve. Applied and Environmental Microbiology, 56(6), pp.1875-1881. 
